\title{
COMUNIDADES QUILOMBOLAS E PROCESSOS DE FORMAÇÃO DE IDENTIDADES NO BRASIL CONTEMPORÂNEO
}

\section{QUILOMBO COMMUNITIES AND THE PROCESS OF IDENTITY FORMATION IN CONTEMPORARY BRAZIL}

\author{
Salete Da Dalt ${ }^{1}$ \\ André Augusto Brandão ${ }^{2}$
}

RESUMO: No Brasil, as discussões em torno dos critérios para reconhecimento das comunidades quilombolas e da garantia de titulação de seus territórios já atravessam duas décadas. Nesse período, houve um alargamento da "noção" de comunidade quilombola. As mudanças, nessa noção, que foram incorporadas pelo Estado possibilitaram a legitimação de uma antiga demanda por reconhecimento de direitos. A partir dessa perspectiva, este trabalho consolida os resultados de uma pesquisa realizada entre 2006 e 2008 em 20 comunidades quilombolas dos seguintes estados brasileiros: Rio Grande do Sul, M. Grosso, Mato Grosso do Sul, Goiás, Espírito Santo, Minas Gerais, Ceará e Maranhão. A questão da identidade e do auto-reconhecimento coletivo como quilombola foi investigada por intermédio das observações de campo e de um conjunto de entrevistas em profundidade, realizadas com lideranças comunitárias locais e com famílias não envolvidas no movimento quilombola.

Palavras-chave: comunidades quilombola; identidade; reconhecimento.

ABSTRACT: In Brazil, the discussions around the criteria for recognition of quilombo communities and their territory title guarantee have been carried out for two decades. During this period, there has been an extension of the "concept" of quilombo community. The changes in this notion that have been incorporated by the State made possible the legitimization of an old demand for recognition of rights. From this perspective, this study consolidates the results of a survey conducted between 2006 and 2008 in 20 quilombo communities of the following Brazilian States: R. Grande do Sul, M. Grosso, M. Grosso do Sul, Goias, E. Santo, M. Gerais, Ceará, and Maranhão. The question of identity and collective self-recognition as a quilombo community was investigated through field observations and a set of in-depth interviews conducted with local community leaders and families who were not involved in the quilombo movement.

Keywords: quilombo communities; identity; recognition.

\footnotetext{
1 Mestre e doutoranda em Política Social pela Universidade Federal Fluminense. Coordenadora do DataUFF.. E-mail: datauff@datauff.uff.br.

${ }^{2}$ Doutor em Ciências Sociais, Professor do Programa de Estudos Pós-Graduados em Política Social da Universidade Federal Fluminense; Diretor Adjunto do DataUFF. E-mail: aapbuff@globo.com.
} 


\section{INTRODUÇÃO}

As discussões públicas e as ações políticas, ancoradas em perspectivas tipicamente multiculturais, têm invadido a cena pública brasileira nas últimas duas décadas. Nesse campo, as questões relacionadas aos problemas advindos das desigualdades entre os grupos de cor ou raça se destacam. Exemplos disso encontramos: a) na Carta Constitucional de 1988 que reconhece a propriedade da terra às comunidades quilombolas; b) na adoção de cotas raciais por inúmeras universidades públicas brasileiras a partir de 2004 (Brandão, 2007); c) na promulgação da lei 10.639/2003 que estabelece o ensino de história e cultura afro-brasileira na educação fundamental; e d) nas políticas públicas voltadas, especificamente, para os quilombolas, tal como as que se encontram em execução no Programa Brasil Quilombola (iniciado em 2004).

Este artigo se insere na discussão relativa às formas de auto-reconhecimento das comunidades quilombolas brasileiras. $O$ material empírico aqui trabalhado é o produto de uma pesquisa mais ampla que avaliou o impacto de ações estruturantes desenvolvidas pelo Ministério do Desenvolvimento Social e Combate à Fome (MDS) junto a esta população. Ainda que nossa pesquisa tivesse como temática central entender como os quilombolas haviam incorporado às suas lógicas produtivas os equipamentos para geração de renda recebidos do governo federal, interessamo-nos, também, por verificar como esses grupos definiam sua identidade.

Especificamente, para este paper, trabalhamos com o material de campo produzido a partir do contato com as comunidades de: Paquetá, em São João da Varjota - PI; Centro-Meio 1, Centro Meio 2 e Bairro Novo, em Penalva-MA; Santa Joana, Morros e Mandioca, em Itapecuru-Mirim MA; Conceição dos Caetanos, em Tururu CE; Bastiões em Iracema - CE; Furnas de Boa Sorte, em Corguinho - MS; Furnas do Dionísio, em Jaraguari - MS; Comunidade Kalunga de Cavalcanti, em Cavalcanti - GO; Porto Coris, em Leme do Prado - MG, Paiol em Bias Fortes - MG; Sapatu e Batatal, em Eldorado - SP, Castelhanos, Nhunguara e Praia Grande, em Iporanga - SP; Mandira, em Cananéia - SP; Manoel Barbosa, em Gravataí - RS e Família Silva, em Porto Alegre - RS.

A etnogênese quilombola foi estudada, nessas 20 comunidades, no decorrer de outra pesquisa que avaliou a implantação de equipamentos para a geração de renda (as chamadas ações estruturantes quilombolas, desenvolvidas em 2003). Sabemos que existem, nesses mesmos estados da federação, outras comunidades quilombolas que não foram ouvidas. A pesquisa, portanto, operou um recorte por meio de uma amostra intencional. Nesse sentido, os resultados aqui apresentados não podem ser generalizados, a priori, para o conjunto das comunidades quilombolas existentes nesses estados. Podem, porém, ser tomados como um indicativo sociológico a respeito do estado atual de um dado processo.

Vale ressaltar, por último, que a questão da identidade e do autoreconhecimento coletivo como quilombola foi investigada por meio das observações de campo e de um conjunto de entrevistas em profundidade, realizadas com lideranças comunitárias locais e com famílias não 
envolvidas no movimento quilombola ${ }^{1}$.

\section{AS MODIFICAÇÕES JURÍDICAS DA TERMINOLOGIA RELATIVA ÀS COMUNIDADES QUILOMBOLAS}

Ainda está para ser feito um inventário preciso dos bastidores da formulação do tão conhecido artigo 68 dos Atos das Disposições Transitórias da Carta Constitucional de 1988. Seja como for, ali se nomeava e se atribuía direitos a um heterogêneo conjunto de comunidades de predominância negra que, salvo raras exceções, não se pensavam em qualquer medida como "remanescentes das comunidades de quilombos".

Arruti (1997) sugere que a noção de "remanescente", que aparece no texto constitucional, deriva de um uso muito específico: a nomenclatura utilizada pelos "agentes oficiais" para indicar as novas etnicidades indígenas que aparecem nos anos 30 e 40 . Naquele momento de intensa etnogênese, foi necessário aos órgãos oficiais que respondiam a demandas por direitos encontrar um limiar classificatório capaz de dar conta de nomear camponeses pobres descendentes de indígenas que reivindicavam pretensos territórios ancestrais. Daí, a noção de remanescentes: esses grupos não seriam formados por camponeses em geral, mas por camponeses com descendência indígena. Ou seja, esses grupos poderiam até ser pensados como indígenas, mas com um adjetivo que lembrava a sua especificidade: "remanescentes".

A constituição de 1988 segue assim

\footnotetext{
1 Todos os nomes citados nas entrevistas foram trocados
} neste paper. essa lógica de nomeação ao se referir aos remanescentes de quilombos; ou seja, não se tratava de disponibilizar direitos para quilombos, mas para populações negras (naquele momento pensadas como exclusivamente rurais) que tinham uma descendência em antigas comunidades quilombolas.

Por outro lado, a definição e a própria imagem de quilombo subjacente seja ao texto constitucional, seja ao próprio senso comum nacional do momento, ligava tais comunidades com ocorrências de fugas de escravos e constituição, a partir daí, de comunidades isoladas que resistiam a ações de recaptura. Para a grande maioria dos brasileiros, naquele ano de 1988, a representação do termo quilombo estava ainda ancorada em Palmares e seu grande herói Zumbi - tratava-se, portanto, muito mais de um estereótipo do que de uma leitura empírica da realidade dessas populações.

No processo de operacionalização do Artigo 68, a dificuldade de produção de direitos à posse da terra, para os "remanescentes das comunidades de quilombos", ficou transparente; e isso por conta de dois aspectos: a) as comunidades negras rurais (e depois também urbanas) existentes no Brasil não são homogêneas entre si; e b) estas não constituem fósseis antropológicos passíveis de serem submetidos a testes precisos de medição.

Do difícil diálogo dos agentes públicos e da intensa pressão do movimento negro e do nascente movimento quilombola, resultou uma progressiva ressemantização do termo "remanescentes das comunidades de quilombos". Nesse ponto, o papel dos antropólogos brasileiros, reunidos em torno 
da Associação Brasileira de Antropologia e de alguns agentes públicos ligados ao Instituto Nacional de Colonização e Reforma Agrária (INCRA), foi fundamental. Importava mostrar que as diversas formas, por meio das quais as comunidades negras vinham se reproduzindo socialmente - seja desde o período escravocrata, seja a partir do pós-abolição - Ihes trazia características gerais muito menos ligadas diretamente ao passado, e muito mais articuladas em torno de processos de organização social.

A vinculação das comunidades quilombolas com um passado de fuga passa a ser somente um dos elementos a serem considerados nesse processo de garantia de direitos. De fato, independentemente da forma como foi construída a comunidade (fuga, ocupação de territórios sem proprietários, ocupações de territórios abandonados pelos antigos proprietários, heranças, doações etc.), o importante era a existência de uma continuada reprodução material e cultural. É nessa direção, portanto, que a legislação passa a ressemantizar o termo "remanescentes das comunidades dos quilombos"; vejamos:

O decreto número 4.887, de 20 de novembro de 2003, em seu artigo $2^{\circ}$ considera:

'remanescentes das comunidades dos quilombos... os grupos étnicoraciais, segundo critérios de autoatribuição, com trajetória histórica própria, dotados de relações territoriais específicas, com presunção de ancestralidade negra relacionada com à resistência à opressão histórica sofrida.

Parágrafo 1ํ Para os fins deste
Decreto, a caracterização dos remanescentes das comunidades dos quilombos será atestada mediante autodefinição da própria comunidade.

Parágrafo $2^{\circ}$ São terras ocupadas por remanescentes das comunidades dos quilombos as utilizadas para a garantia de sua reprodução física, social e cultural.'

Mais a frente, o mesmo decreto, em seu artigo $3^{\circ}$, parágrafo $4^{\circ}$, aponta que "A autodefinição de que trata o parágrafo $1^{\circ}$ do artigo $2^{\circ}$ deste Decreto será inscrita no Cadastro Geral junto à Fundação Cultural Palmares, que expedirá certidão respectiva na forma do regulamento".

Esse artigo $3^{\circ}$ ensejou que o INCRA produzisse, quase dois anos depois, uma Instrução Normativa específica (Número 20, de 19 de setembro de 2005) para regulamentar os procedimentos relativos a tal inscrição nos Cadastro Geral. Nesse documento legal, é reafirmado o conceito de "remanescentes das comunidades dos quilombos" e o de "terras ocupadas por remanescentes das comunidades dos quilombos"; que aparecem no Decreto de 2003. No item "CERTIFICAÇÃO", aparecem as seguintes diretrizes:

'Artigo 7ํ A caracterização dos Remanescentes das Comunidades de Quilombos será atestada mediante auto-definição da comunidade.

Parágrafo $1^{\circ} A$ auto-definição será demonstrada através de simples declaração escrita da Comunidade interessada, nos termos do artigo $2^{\circ}$ do Decreto 4.887/2003. 
Parágrafo $2^{\circ}$ A auto-definição da Comunidade será certificada pela Fundação Cultural Palmares- FCP, mediante Certidão de Registro no Cadastro Geral de Remanescentes das Comunidades de Quilombos do referido órgão, nos termos do parágrafo 4, do artigo 3, do Decreto 4.887/2003.

Parágrafo $2^{\circ} \mathrm{O}$ processo que não contiver a Certidão de Registro no Cadastro Geral de Remanescentes das Comunidades de Quilombos da FCP será remetido pelo INCRA, por cópia, àquela Fundação, para providencias de registro, não interrompendo o prosseguimento administrativo respectivo. 1

$\mathrm{Na}$ mesma direção dos textos legais, citados acima, em 2004 o Governo Federal lança o Programa Brasil Quilombola. Por intermédio de um documento que comporta 48 páginas (incluindo os anexos), a Secretaria Especial de Políticas de Promoção da Igualdade Racial (SEPPIR) também investe nas argumentações que ressemantizam o conceito de remanescente de quilombo. $O$ argumento principal é que se para os negros escravizados a constituição de quilombos após a fuga era a única possibilidade de sobrevivência com liberdade; depois da "abolição formal da escravatura", a formação de comunidades autônomas "tornou-se um imperativo de sobrevivência, visto que a Lei Áurea os deixou abandonados à própria sorte. Desprovidos de qualquer patrimônio, vivendo na mais absoluta miséria, os negros recusaram-se a conviver num mesmo espaço com aqueles que os consideravam inferiores e não os respeitavam na sua humanidade. Além disso, ainda tiveram que enfrentar as resistências e os preconceitos de uma sociedade o qual desprezava sua cultura e a sua visão de mundo." (PROGRAMA BRASIL QUILOMBOLA, p. 9)

O documento prossegue afirmando que várias comunidades permaneceram agregadas, ainda que nem sempre isoladas, até 0 presente. Mas não seriam traços relativos à homogeneidade física que os caracterizariam como remanescentes de quilombos: "É mais plausível afirmar que a ligação com 0 passado reside na manutenção de práticas de resistência e reprodução do seu modo de vida num determinado local onde prevalece a coletivização dos bens materiais e imateriais." (PROGRAMA BRASIL QUILOMBOLA, p. 9). Indo mais além, o documento dialoga com o conceito de etnia:

'Deste modo, comunidades remanescentes de quilombo são grupos sociais cuja identidade étnica os distingue do restante da sociedade. É importante explicitar que, quando se fala em identidade étnica, trata-se de um processo de auto-identificação bastante dinâmico e não se reduz a elementos materiais ou traços biológicos distintivos, como cor da pele, por exemplo.' (PROGRAMA BRASIL QUILOMBOLA, p. 9)

$\mathrm{O}$ argumento central desse documento fica em torno da forma de caracterizar os remanescentes de quilombos como um grupo étnico. Vemos referências implícitas a Weber (2001), no seu famoso capítulo sobre relações étnicas e raciais, e a Castells (1999), quando o documento marca o caráter de auto-definição da etnia e da 
identidade, que teriam como materiais primas possíveis tanto uma "ancestralidade comum", quanto "formas de organização política e social" e, ainda, "elementos linguísticos e religiosos". A partir desse pressuposto, 0 que singularizaria as comunidades quilombolas e atestaria uma proximidade entre os quilombos do passado e os quilombos atuais seriam "as práticas econômicas desenvolvidas, cujos modelos produtivos agrícolas estabelecem uma necessária integração à microeconomia local com vistas à consolidação de um uso comum da terra" (PROGRAMA BRASIL QUILOMBOLA, p. 10).

Há duas questões a serem discutidas aqui:

a) Em nossa pesquisa, que abarcou 65 comunidades remanescentes de quilombos, das 2.058 famílias que responderam a um questionário socioeconômico, somente $6 \%$ apontavam a terra como coletiva e somente cerca de $10 \%$ produziam em regime comunitário;

b) Qualquer cientista social que conheça comunidades rurais não quilombolas do nordeste ou comunidades ribeirinhas, em geral da Amazônia brasileira, sabe muito bem que não existem diferenças organizacionais do ponto de vista político e econômico entre estas e uma comunidade quilombola vizinha. Em geral, as diferenças, estão exatamente nos casos de manutenção de uma especificidade fenotípica negra, ou de manutenção de alguns traços culturais no campo da forma de viver, a religiosidade católica, ou, ainda, na manutenção de danças e de uma musicalidade tradicionais.

A grande relativização observada nas legislações e no documento Brasil
Quilombola abre caminho para inúmeras discussões de demandas por direitos que se dispõem fundamentalmente nos quadros de uma nova agenda de políticas públicas. Essa agenda aponta a necessidade de priorizar, em algumas políticas setoriais, os grupos que acumularam desvantagens sociais associadas a processos históricos de discriminação e exclusão social (como os indígenas, mas também os negros em geral e os "remanescentes de quilombos" em particular).

Mais especificamente, não somente a posse da terra aparece hoje como um direito garantido aos quilombolas. O Programa Brasil Quilombola, por exemplo, vem desenvolvendo ações em áreas, como eletrificação, saneamento e construção de moradias. Desde 2003, um grande número de comunidades quilombolas recebe cestas básicas oriundas, ainda, do antigo Programa Fome Zero (hoje incorporado, como política, ao Ministério do Desenvolvimento Social e Combate à Fome). Esse mesmo ministério, entre 2003 e 2006, entregou a 150 comunidades equipamentos para geração de renda. Para não falar da política nacional de assistência que propõe a criação de equipamentos assistenciais específicos (os chamados Centros de Referência da Ação Social - CRAS), para essas comunidades.

Nessa correlação entre direitos e identidade, surgem, por sua vez, perspectivas de demanda por reconhecimento, a partir da autoidentificação. Vejamos, agora, como os "remanescentes de quilombos" se auto-definem. 


\section{AS FORMAS DE AUTODEFINIÇÃO}

No conjunto de entrevistas realizadas com lideranças comunitárias e moradores em geral de comunidades quilombolas, uma grande parte dos entrevistados relacionava a sua "qualidade" de quilombola ao passado de escravidão. Vejamos alguns exemplos.

a) Liderança da Comunidade Centro Meio 2, Município de Penalva - MA

Pesquisador: Agora deixa eu the perguntar sobre a comunidade quilombola. Vocês se tornaram uma comunidade quilombola tem pouco tempo?

- Tem pouco tempo.

Pesquisador: Está certo. E o senhor acha que o pessoal daqui entendeu o que é ser quilombola?

- Entendemos.

Pesquisador: E o senhor entende o que por isso?

- Comunidade quilombola era no tempo, com relação ao tempo dos escravos, era só escravo, aí eles juntou o pessoal e eles acharam que nós deveria também ser quilombola, porque nós não somos outra classe, norte e nordeste é mesmo quilombola.

b) Morador da Comunidade de Manoel Barbosa, Município de Gravataí-RS

Pesquisador: E a senhora consegue entender o que é ser quilombola?

- Entender... nem sei... eu acho que é por causa dos escravos. c) Liderança da comunidade de Centro Meio 1, Município de Penalva - MA

Pesquisador: O que é, para a senhora, ser quilombola?

- Pra mim, quilombola é aquelas pessoas que vieram escravizados, que foram escravizados e que são descendência de escravos.

Pesquisador: A senhora acha que eles entendem assim?

- Do jeito que a gente explicou pra eles, eu acho que sim.

Pesquisador: Aí todo mundo aderiu?

- É todo mundo é quilombola.

d) Liderança da comunidade de Paquetá - São João da Varjota - PI

Pesquisador: $O$ senhor acha que 0 pessoal da comunidade já entendeu o que é ser uma comunidade quilombola?

- Muita gente já entendeu, nós somos uma comunidade do quilombo, eu sei, com certeza, que entendo já um pouco, participando das reuniões, que nós viemos lá dos sofrimentos dos escravos e nós vêm se organizando e através da nossa organização a gente cria as associação pra nos defender e ser convidados para reuniões e seminários pra discutir nossos assuntos não só pra trazer benefícios, mas pra ter conhecimento do que nós somo e do que nós precisa.

e) Liderança da comunidade de Furnas de Boa Sorte - Corguinho - MS

Pesquisador: Você é quilombola? O 
que é ser quilombola?

- Eu me considero como quilombola dos que vieram do tempo da escravidão.

f) Morador da comunidade Porto Coris, Leme do Prado - MG

Pesquisador: O que é ser quilombola? O senhor saberia me dizer?

- O que é ser quilombola... é que nós somos descendentes de escravos, né.

As imagens acima delineadas, construídas por lideranças e por moradores em geral de comunidades auto-declaradas quilombolas, são somente um exemplo de uma associação que ouvimos frequentemente durante a pesquisa. De fato, as populações locais estavam somente reafirmando aquilo que muito provavelmente ainda representa o senso comum nacional: a ideia de que os quilombos existentes hoje remontam ao passado de escravidão. Parte significativa das lideranças e dos moradores em geral, com os quais mantivemos contato em 2006 ainda não haviam ressemantizado o conceito de quilombola e referiam sua existência, como comunidade quilombola, a uma derivação direta ou mesmo a uma descendência de escravos.

Há, no entanto, outras imagens que são mobilidades pelos quilombolas para explicar sua qualidade atual. Estas, em geral, transitam pela aproximação entre quilombolas e negritude, sem referências à escravidão, trata-se de uma perspectiva que já ressamantizou o termo em relação a seu uso inicial de remanescente de um passado de escravidão e fuga para a liberdade. a) Morador da comunidade de Bastiões, Município de Iracema - CE

Pesquisador: Deixa eu falar de outra coisa com a senhora, aqui é uma associação quilombola. O que é para a senhora ser quilombola?

- A gente não tinha conhecimento, mas depois que ela [a liderança comunitária] começou a trabalhar com isso, a comunidade quilombola, a gente já sabe que é na terra que começa com os negros né?

b) Liderança da comunidade de Bairro Novo, Município de Penalva - MA

Pesquisador: E quando você explica isso para eles..., o que é ser quilombola?

- Eu explico assim, ser quilombola é um negro, por que hoje em dia o trabalho que a gente faz é negro. $O$ negro e quilombola não são tudo diferente, as vezes tem a cor mulatinha, mas são negros.

c) Liderança da comunidade de Conceição dos Caetanos, Município de Tururu - CE

Pesquisador: $O$ que a senhora entende por ser quilombola?

- Eu entendo porque ser quilombola é se assumir como negro. E eu me assumo. Se fosse tudo pela minha opinião aqui nós tinha se organizado pra ficar só como comunidade negra, o pessoal de fora que vivesse aqui podia morar, mas não como chefe, a gente respeitava eles, eles respeitava a gente, mas eu me assumo mesmo como quilombola, eu tenho orgulho mesmo de ser negra, e como eu tenho 
orgulho de ser negra foi registrada a comunidade como comunidade quilombola.

Por outro lado, em comunidades do Estado de São Paulo, encontramos representações nas quais os moradores relacionam a noção de quilombola às políticas públicas ou a possibilidades de defesa da população negra. Vejamos.

a) Morador da comunidade de Castelhanos, Município de Iporanga - SP

Pesquisador: O que vocês entendem por ser quilombola?

- ...o pai criou doze filho aí numa área de terra e aí de repente apareceu um malandro, enrolando ele e fez ele assinar um documento como se tivesse arrendando a propriedade e praticamente alugou o terreno dele, onde ele criou doze filhos e os filhos foram se criando ali, de repente veio um despejo pra ele sem nem saber o que tinha assinado, porque antigamente se usava as pessoas, os grandes fazendeiros, que tem aí, eles usavam o povo de má fé, aí ele vinha aí e falava, não, eu sou rico eu moro em São Paulo e aí trazia um quilinho de carne, daqui a pouco pegava a assinatura do coitado pra arrendar igual aconteceu com o meu pai (...) Então, se o quilombola existisse isso não teria acontecido, porque ninguém enganava hoje, na época minha o cara vinha aí..., se você perguntar pra várias pessoas, tem gente que trocou o terreno até por comida de porco, na época. Um comprava meio alqueire e cercava cinco, dez. Esse era o problema na região.

Pesquisador: Certo, mas vocês conseguem entender $O$ que é ser quilombola?

- O quilombola, pelo que a gente acompanha, ele já tem muito tempo que existe, ele falta ser reconhecido, o direito dos quilombolas, mas ele já ha muito tempo existe, agora que ele entrou porque o povo está reconhecendo ele no direito que ele tem, porque pra falar bem a verdade, teve uma época aí que preto não tinha o direito de nada, até quase que hoje existe, mas muito pouco, mas o preto já não tinha direito o emprego, pra falar bem a verdade ele era excluído, e hoje não o quilombola veio trazendo o direito dos negros e hoje ele tem muito direito e eu acho que o quilombola ele está hoje até de parabéns porque ele está sendo utilizado, ele está ajudando o povo.

b) Liderança da comunidade de Castelhanos, Município de Iporanga - SP

Pesquisador: $O$ que a senhora entende por ser quilombola? Como a senhora explicaria para alguém?

- Pra mim o quilombo é uma coisa assim que já veio do governo federal pras pessoas que tinha as terras deles, meu pai foi um que preservou muito as terras dele, de onde ele nasceu e morreu, foi bom por que veio essa lei e essa terra ficou pras famílias, quer dizer ele não vendeu terra na época, mas teve gente que vendeu, meu pai foi bom de cabeça por que sabia que os filhos dependiam da terra pra sobreviver.

c) Morador da comunidade de Mandira, Município de Cananéia - SP

Pesquisador: $E$ o que 0 senhor entende por ser quilombola? 
- Entendo que é uma coisa, que pelo menos ele protege o preto. Por que quando não tinha esse negócio de quilombo o preto só vivia ferrado. Agora tem mais valor, que antes o preto não tinha valor.

Nessa perspectiva, a palavra quilombola remetia os entrevistados a um tipo de política de proteção social que valoriza os pretos, por um lado, e lhes garante a posse da terra. Deriva, daí, o fato de os moradores (lideranças ou não) se referirem ao "quilombo" e ao "quilombola" como um ente externo, que veio de fora para auxiliá-los em suas demandas por terra e garantir que eles não fossem mais lesados em suas relações com os fazendeiros.

Essa ressignificação local dos termos "quilombo" e "quilombola" tangencia uma outra perspectiva muito encontrada nas comunidades que aponta para os ganhos adquiridos - sob a forma de "benefícios" ou "direitos" - quando da descoberta de que a comunidade é remanescente de quilombolas. Esse tipo de vinculo foi estabelecido por muitas lideranças e por alguns poucos membros das comunidades não vinculados com a liderança, em vários estados brasileiros; vejamos alguns exemplos.

a) Morador da comunidade de Bastiões, Município de Iracema - CE

Pesquisador: E a senhora acha que as outras famílias negras entenderam o que é ser quilombola?

- Eu acho que entenderam. Têm uns que entendem e têm outros que não.
Pesquisador: E a senhora acha que o pessoal quer ser quilombola?

- Bom, de primeiro não queriam de jeito nenhum, mas hoje já estão querendo.

Pesquisador: $E$ porque eles não queriam antes?

- Por que queriam ser branco. E hoje depois que apareceu alguns benefícios, o pessoal estão querendo receber o beneficio e está tudo querendo ser negro. Descobriu um jeito... que tem gente que nunca pensou que queria ser negro..., nessa época está querendo ser negro.

b) Liderança da comunidade de Bastiões, Município de Iracema - CE

Pesquisador: $O$ que é ser remanescente de quilombo?

- Que nós somos pretos, negros como é chamado atualmente. Agora, com uns projetos que vem pra cá, todo mundo quer ser negro. Todo mundo quer ser remanescentes só que não é.

c) Liderança da comunidade de Conceição dos Caetanos, Muncicípio de Tururu - CE

Pesquisador: $\mathrm{E}$ a senhora acha que todo mundo aqui aceita ser quilombola?

- Não, todo mundo não aceita não.

Pesquisador: Mais ou menos...

- Todo mundo só aceita ser quilombola quando vêm as cestas básicas: 'ai, eu sou negro também'. 
d) Liderança da comunidade de Morros, Município de Itapecuru-Mirim - MA

Pesquisador: Deixa eu lhe perguntar de novo: o pessoal entende que essa comunidade é remanescente do quilombo?

- Muitos não, mas pouco...

Pesquisador: Mas o que eles acham disso?

- Eles gosta.

Pesquisador: Por que é que você acha que eles gostam?

- É como se diga, nós gosta porque através disso é que nós, hoje está vindo muito benefício pra gente, né, inclusive a nossa raça também, em primeiro lugar. Eu espero que venha cada vez mais... o governo manda pra gente.

e) Liderança da comunidade Kalunga de Cavalcanti, Município de Cavalcanti - GO

Pesquisador: Nesse trabalho que o senhor está chamando de aperfeiçoamento, como é que foi o processo de convencer a comunidade, mostrar à comunidade que ela era quilombola?

- Foi através de reunião, de casa em casa, foi através do benefício que está chegando pra gente. Como a gente está recebendo por ser quilombola, foi de preservar a cultura da gente, como a gente não deve trocar ela por nada. Essa cultura nossa é nosso tesouro, não devemos pisar nela achando que tem outra melhor, outra pior.

Pesquisador: O senhor acha que, quando foram chegando os benefícios, foi ficando mais fácil de convencer o pessoal?
- Muito mais fácil. Muito mais fácil. Quando chegava o benefício, o primeiro beneficiário era aquela pessoa que era contra. A gente já faz questão de entregar pra ele, no caso, o cobertor, né. Teve uma doação de cobertor, o João, assim que a associação faz ofício e manda, vem, agora tem um tempo que a gente não faz, mas vinha todo ano e vinha cobertor, roupa de frio. Aquelas famílias que a gente via que era mais escuterada a gente fazia, era primeira a receber, daí a pouco foi chegando consenso, daí a pouco veio a moradia pras comunidades quilombolas, veio as construção de banheiro também, não, primeiro veio a luz pra todos, principalmente pras comunidades quilombolas, as outras vão ganhar, mas primeiro as comunidades quilombolas, tem prioridade, veio esses banheiros também prioridade para os quilombolas e várias doaçãozinha também. A gente tem, foi também pela justiça, foi isento por ser quilombola, de estar sendo imprensado pela mão da polícia isso foi criado também uma fortaleza entre nós.

f) Liderança da comunidade de Mandira, Município de Cananéia - SP

Pesquisador: O que você e as outras pessoas entendem que é ser quilombola?

- Por ser quilombola, você fala assim sobre o direito, hoje tem uma vantagem muito grande em ser quilombola, tem leis favoráveis, estadual, municipal e federal. Você se reconhece como negro, que é uma coisa que jamais a gente ia pensar estar nessa caminhada, e tem vários trabalhos que a gente faz por ser comunidade quilombola. Temos uma equipe de assessoria de Eldorado e fazemos trabalho 
em todo estado, tem essa vantagem né, é a união das comunidades.

Muitos moradores em geral e lideranças das comunidades quilombolas acreditam que, para conseguir benefícios, é necessário se assumir como quilombola, ou pelo menos assinar a ata da reunião na qual a associação se afirma como quilombola. Vale lembrar que o texto do Programa Brasil Quilombola, veiculado pelo Governo Federal, traz um anexo V (página 47), intitulado "Como Solicitar o Certificado como Associação Quilombola". Transcrevemos abaixo o texto deste anexo:



Há, também, o anexo VI (página 48), denominado "Como se cadastrar no INCRA".

\section{"MODELO}

REQUERIMENTO

ILMO. SENHOR SUPERINTENDENTE REGIONAL DO INCRA DO ESTADO DE A COMUNIDADE DE QUILOMBOS, DENOMINADA..............................., COM SEUS REPRESENTANTES LEGAIS, ABAIXO ASSINADO, VEM MUI RESPEITOSAMENTE A PRESENÇA 
DE V. SA. SOLICITAR A DEMARCARÇÃO DA ÁREA DENOMINADA LOCALIZADA NO MUNICÍPIO NO ESTADO DE E EM SEGUIDA A TITULAÇÃO DAS TERRAS, CONFORME NOSSO TERRITÓRIO, DE MODO COLETIVO, NOS TERMOS DO ART. 68 DOS ATOS DAS DISPOSIÇÕES CONSTITUCIONAIS TRANSITORIAS ADCT, DA CONSTITUIÇÃO FEDERAL DE 1988, COMBINADOS COM OS ARTIGOS 215 E 216 DA CONSTITUIÇÃO FEDERAL, BEM COMO OS TERMOS DO DECRETO N 4887, DE 20 DE NOVEMBRO DE 2003, E ARTIGO ....... DA CONSTITUIÇÃO ESTADUAL DO ESTADO DO (SE TIVER???). A NOSSA ÁREA ESTÁ ESTIMADA EM APROXIMADAMENTE HECTARES, LIMITANDO-SE NAS MARGENS ESQUERDA DO RIO DO IGARAPE DA FAZENDA... DO SENHOR FULANO DE TAL AO NORTE AO SUL (CARACTERIZAR DA MELHOR FORMA POSSÍVEL). DECLARAMOS AINDA QUE NOSSA COMUNIDADE SE RECONHECE COMO COMUNIDADE DE QUILOMBOS, DO QUE FALA O DECRETO FEDERAL 5.051, DE 19 DE ABRIL DE 2004, DE QUE TRATA A RESOLUÇÃO 1.690, DA ORGANIZAÇÃO INTERNACIONAL DO TRABALHO, OIT. INFORMAMOS AINDA QUE VIVEMOS A MAIS DE 200, 250 OU 300 ANOS NO LOCAL, RESISTINDO A TODOS OS TIPOS DE DIFICULDADES PARA MANTER A UNIDADE DO NOSSO POVO, PARA TANTO SOLICITAMOS DE V.SA. MANDAR REALIZAR A VISTORIA EM NOSSO TERRITÓRIO, PARA EFETIVAR A TITULAÇÃO TÃO SONHADA PELO POVO NEGRO.

$\mathrm{Na}$ Oportunidade Anexamos os Seguintes Documentos:

01 - Cópia dos Documentos Pessoais (Cl, CPF, Título de Eleitor) do Presidente da Associação

02 - Cópia do CNPJ da Associação, Devidamente Atualizado (Em Dia)

03 - Cópia do Registro Especial do Nosso Estatuto

04 - Cópia da Ata da Reuniao de Posse da Diretoria da Comunidade e da Solicitação do Pedido de Titulação.

05 - Cópia do Diário Oficial do Estado, Publicando.... (Se Tiver)

06 - Cópia da Ata de Fundação

07 - Declaração de Autoreconhecimento.

NESTES TERMOS, PEDE E ESPERA DEFERIMENTO.

MUNICÍPIO (UF), $\mathrm{DE}$ 2004

ASSINATURA DO PRESIDENTE DA ASSOCIAÇÃO QUILOMBOLA"

Como vemos, parece que estamos diante de um processo de etnogênese na qual o papel ativo do estado brasileiro se mostra com força. Sabemos que toda identidade (inclusive a étnica) é produto de um processo de construção. Assim, não nos deve espantar o fato de que, em certos contextos políticos, esta construção envolva não somente as comunidades que serão alçadas à condição de um "grupo étnico" (ou como diz o texto do Programa Brasil Quilombola: "grupos sociais cuja identidade étnica os distingue do restante da sociedade" - página 9), mas também um 
conjunto de agentes externos às comunidades. Nesse caso específico, principalmente o estado e o movimento negro $^{2}$ trabalharam na direção de construir as bases para um processo de etnogênese que rivaliza em tamanho com 0 renascimento dos grupos indígenas brasileiros no século XX. Em nosso trabalho de campo, ouvimos, de lideranças e moradores em geral das comunidades, um significativo número de referências ao que estamos chamando de agentes externos. Vejamos alguns exemplos.

a) Liderança da comunidade Família Silva, Porto Alegre - RJ

Pesquisador: O que é para vocês ser uma comunidade quilombola?

- Eu não sabia que eu era um quilombola, fui saber há pouco tempo, com a doutora Maria, do movimento negro.

b) Liderança da Comunidade de Conceição dos Caetanos, Município de Tururu - CE

- O dia do negro a gente sempre comemora o dia 20 de novembro.

Pesquisador: Isso é uma iniciativa da associação?

- Não, da comunidade, não pela associação.

Pesquisador: Da comunidade da igreja?

\footnotetext{
${ }^{2}$ É claro que outros agentes com alcance mais localizado também foram importantes em determinados contextos. Em nossa pesquisa foi citada a igreja através do trabalho de padres específicos e também o Movimento dos Atingidos por Barragens.
}

- Da igreja...

Pesquisador: Todo 20 de novembro. De quem foi essa ideia? Foi do padre?

- Não da liderança mesmo, minha mãe. Ela já sabe contar mais, porque eu sou mais nova, já aprendi com ela. Antes a gente não tinha reconhecimento, a gente não sabia o que era comunidade negra, a gente não tinha movimento, mas aí tinha uma moça que mora em Salvador, prima da gente, ela passou todo esse conhecimento pra gente, através de livro, através de canto, através de histórias.

Pesquisador: Essa prima de vocês...?

- É do movimento negro, a Maria... E aí a minha mãe ficou com esse conhecimento e ai a gente começou a participar. Eu, ela e aí ela, quando você passa a participar de uma coisa você fica por dentro, aí ela já ficou por dentro do que era comunidade negra, dos direitos que os negros tinham, aí foi a partir daí que a gente começou, em 20 novembro tem a festa da padroeira e dia de Zumbi a gente comemorava. 20 de novembro, dia de Zumbi a gente comemora, a gente faz missa, dança africana, música.

Pesquisador: Como é que vocês aprenderam essas danças africanas?

- Através da Maria e depois através do axé, através dos grupos de movimento negro de Fortaleza que a gente conhece...

c) Liderança da comunidade de Centro-Meio 1, Município de Penalva - MA

Pesquisador: Me diga outra coisa, vocês são uma associação quilombola? 
- Somos sim senhor.

Pesquisador: A associação já está com nome? Qual é o nome?

- Associação Comunitária Deus é Amor Quilombolas.

Pesquisador: Está certo. Vocês mudaram recentemente esse nome?

- É porque não tinha quilombola, quando a gente foi se registrar já tinha a associação que já era registrada como Deus é Amor.

Pesquisador: $E$ como é que vocês resolveram virar uma associação quilombola?

- É por que através da representante da $A C O N E R U Q^{3}$, ela é muito chegada a minha pessoa e ela começou a me convidar e ficar esperando outra reunião em Penalva. Aí eu comecei a andar com ela, faz 4 anos a nossa filiação que foi lá em Codó. E lá eu me filiei, ela disse que senão a gente nunca ia ter nada pra comunidade. De lá pra cá, eu venho contribuindo todo o tempo e graças a Deus nós estamos quites na ACONERUQ, e agora, quando veio agora pra botar pro quilombo eles perguntaram e eu disse: se nós somos quilombolas tem que ser quilombolas e temos que aceitar o que a gente é.

Pesquisador: Aí vocês fizeram uma ata?

- Fizemos.

Pesquisador: Como é que foi esse processo?

- Aí a gente lavrou uma ata, de auto

\footnotetext{
${ }^{3}$ Trata-se da Associação das Comunidades Negras Rurais Quilombolas do Maranhão.
}

definição, porque nós temos a coordenadora, são seis instrutores aqui no mato que ficam incentivando. $A$ coordenadora dá reuniões com a gente, a gente fica sempre entrando em contato com ela e ela que se colocou à disposição de entrar em contato com a Fundação. Foi ela que lavrou a ata pra gente. Explicou pra gente. A gente fez e voltou pra ACONERUQ.

Pesquisador: Você explicou isso pra comunidade e o pessoal aceitou?

- Aceitou fazer a auto definição, primeiro eu trouxe a proposta expliquei a nossa classe que somos negros e o pessoal aceitou muito bem e combinaram que podia fazer, até porque nós temos que se declarar aquilo que nós somos. A gente não pode fugir daquilo que a gente é.

Pesquisador: Você acha que o pessoal entendeu o que é ser quilombola?

- Eu acho que deu pra entender. Talvez $100 \%$ não, mas $80 \%$ sim.

d) Liderança da comunidade de Praia Grande, Município de Iporanga - SP

Pesquisador: Como vocês descobriram que eram quilombolas?

- Foi um trabalho da MOABE [Movimento dos Atingidos por Barragens], ... mas tem um eixo, um lado, que começa pela igreja, quer dizer, não tinha uma lado, praticamente pra nós foi a igreja...

Pesquisador: Mas vocês começaram a ser quilombolas quando?

- Ah tá, aí começou-se a estudar a cultura do povo aqui, como é que se vivia e aí identificou-se que era família quilombola. 
Pesquisador: Quem fez este estudo, comunidade remanescente de quilombos? foram vocês mesmos?

- A igreja, a Moabe, aí já veio o trabalho de antropologia também, pra fazer o reconhecimento da área, o relatório das área, né.

e) Liderança da comunidade de Porto Coris, Município de Leme do Prado - MG

Pesquisador: Você falou que a comunidade foi reconhecida como quilombo, o que é ser quilombola para você?

- Até um tempo atrás nem eu sabia o que era quilombola eu passei a saber a partir do momento que foram construir uma barragem na nossa área e veio um pessoal aí da Palmares fazer uma pesquisa e aí a gente conta as histórias, e aí eles passaram a informação para a gente e falou que nós era quilombola e se nós queríamos ser titulados e nos vibramos muito com isso por que até a gente conhecer o que era a gente, levou muito tempo e aí eles titularam a gente.

Pesquisador: Mais essa instituição vinha até vocês para fazer esse trabalho?

- A Palmares mandou um antropólogo para fazer um estudo e aí foi reconhecido.

Pesquisador: Mais vocês já sabiam da sua origem?

- Sim, nos já sabia de toda a história, mais não sabíamos o que era um quilombo.

f) Liderança da comunidade de Paiol, Município de Bias Fortes - MG

Pesquisador: Por que vocês são uma

- Nós nem sabia, mas para nós é muito bom ser quilombolas... para a nossa comunidade.

Pesquisador: Mais que tipo de informação veio para vocês chegarem àconclusão que vocês eram quilombolas?

- Foi o livro né... foi a primeira informação que nos tivemos feito uma história... pelo padre Flávio... um levantamento.

Para além disto, verificamos que o entendimento que as lideranças e os moradores, em geral, das comunidades expressam acerca do que é ser uma comunidade quilombola ou ser um quilombola "individual" é bastante difuso e impreciso.

a) Moradores da comunidade de Centro Meio 2, Município de Panalva - MA

Pesquisador: Mas como é que você descobriu que era quilombola?

- Porque meu padrinho já esteve viajando pra fora e ele agora tem a ata, fez a ata da gente, né, que era pra registrar, inclusive eu acho que já chegou, porque ele já registrou todo mundo como quilombo. Que já está na ata.

Pesquisador: Mas o pessoal todo entendeu bem o que é esse negócio?

- Todo mundo assinou.

Pesquisador: Todo mundo quis ser quilombola?

- Todo mundo quis. 
- É teve reunião aqui, agora, semana passada, lá em casa, elas tiveram, foi na quinta-feira que elas tiveram lá ajeitando pra saber quem era quilombo e quem não era.

Pesquisador: Mas como é que se descobre quem é quilombo? Você falou assim: "pra saber quem é quilombola e quem não é". Como é que se descobre isso? Tem diferença de quem é quilombola pra quem não é quilombola?

- Está na ata, então aí deram um prazo de três meses pra decidir e agora é que a gente mudou a ata.

Pesquisador: Entendi. Todo mundo quis ser quilombola?

- Eu acho que é porque é alguma coisa que está vivo, né. $E$ a gente acha que é, então a gente tem que aceitar né, porque se a gente é.

Pesquisador: Está certo. Mas você acha que o pessoal entendeu o que é ser quilombola?

- Eu creio que eles entenderam, até porque meu padrinho deu muito tempo pra todo mundo pensa, né, pra todo mundo pensa e sabê o que é que queria, então foi isso que todo mundo quis, então ele deu um prazo, praticamente de três meses, depois de três meses que ele chamou todo mundo de novo pra ver o que queria, né, e aí todo mundo assinou.

Pesquisador: Mas uma coisa é as pessoas terem aceitado ser quilombola outra coisa é as pessoas saberem o que é ser quilombola. Se eu perguntar pra senhora agora o que é ser quilombola, o que a senhora me responderia?

- Ah, eu sei lá eu diria assim, que aquele negócio de ser preto, escravo, aquele negócio todo, né, que hoje praticamente não existe mais isso, esse negócio de escravo, acho que hoje não existe mais isso. Então, antigamente, o pessoal existia assim, quem era quilombola, quem era escravo, aqueles que chamavam preto, negro e hoje eu acho que todo mundo tem que ser isso, só esse negócio de escravidão que não existe mais isso, esse negócio de escravidão que não existe mais, não.

- Exatamente é isso que falta de alguém chegar e dizer olha vocês vão participar de tal projeto assim, do quilombo e tal, as pessoas precisam saber o que é..., a eu vou participar, vou fazer uma ata e pronto..., tem que saber. Eu não sei o que é um quilombo, o que eu preciso ser, o que eu preciso saber por que, por exemplo, uma entrevista dessa em São Paulo, em Brasília e perguntar: "O que é ser do quilombo?" Eu não saberia responder, porque eu não tive nenhuma orientação.

Pesquisador: Entendi.

- Eu acho que falta mais chegar e fazer uma reunião, e dizer o que é você ser do quilombo, o que é participar de uma comunidade rural, como é que você tem que trabalhar com a terra, uma série de coisas, tem que cultivar direito o que você tem, porque se você não cultivar direito, você vai perder, então alguém tem que ensinar, porque se a pessoa não sabe ler, vai saber o que é o quilombo? Precisa de alguém pra instruir, pra ensinar, esse aqui é o quilombo que você vive vai acabar o Brasil escravagista, negro, preto branco vai ser todo mundo igual, vai acabar com preconceito, com o racismo, alguém tem que orientar o que é... Um professor, alguém que 
saiba e diga, é isso, é isso, tirar um tempo deles pra nos mostrar o que é ser quilombo, ser produtor rural, agropecuária, esse tipo de coisa, a gente não sabe o que é realmente devido à falta de instrução.

b) Morador da comunidade de Paquetá, Município de São João da Varjota $-\mathrm{PI}$

Pesquisador: Agora, voltando àquela conversa sobre as comunidades quilombolas, você acha que o pessoal entendeu?

- $80 \%$ das pessoas entendem o que é o quilombola.

Pesquisador: E ninguém discorda?

- Não. Nunca vi ninguém reclamando.

Pesquisador: Todo mundo aceitou?

- Todo mundo aceitou de boa vontade, de peito aberto graças a Deus!

Pesquisador: E o que você entende por ser um quilombola?

- Eu até que sou um pouco por fora do que é ser um quilombola, não entendo muito não... eu participei e estou gostando. Não tenho nada do que reclamar.

c) Morador da comunidade de Mandira, Município de Cananéia - SP

Pesquisador: $O$ senhor acha que 0 pessoal da comunidade já entendeu o que é ser quilombola?

- Não sei, eu não entendo muita coisa, mas não sei se entendem ou não. Tudo agora é quilombola, mas eu mesmo não entendo não.

d) Morador da comunidade de Sapatu, Município de Eldorado-SP

Pesquisador: Você acha que o pessoal da comunidade entendeu o que é ser quilombola?

- Eu acho que o pessoal entende. Eu, pelo menos, estou entendendo que o principal nosso aqui é a terra. Se amanhã acontecer algo, nós temos a terra.

Essa configuração de entendimentos difusos leva a situações nas quais os moradores não conseguem estabelecer um consenso acerca do fato de serem parte de uma comunidade remanescente de quilombos. Encontramos esse tipo de discordância especificamente em três comunidades que fizeram parte de nossa pesquisa.

Em Conceição dos Caetanos (Tururu CE), um bairro rural, situado a cerca de 40 minutos, de carro, da sede do município, os motivos da discordância parecem, principalmente, de ordem simbólica. No bairro, a grande maioria das famílias são oriundas de um primeiro proprietário negro que teria adquirido terras naquela localidade - a liderança mais proeminente da comunidade é neta desse fundador. Depois da morte deste, alguns de seus herdeiros venderam propriedades para pessoas de fora e a área começou a ser invadida por grileiros. Hoje, no bairro, moram algumas poucas famílias brancas que herdaram terrenos ou que os compraram recentemente (encontramos famílias que haviam adquirido casas há cerca de cinco 
anos). Essas famílias, obviamente, não desejam que a comunidade seja quilombola e muito menos aceitam a titulação coletiva da área. Por outro lado, um número relativamente elevado de famílias negras, descendentes do fundador, também não aceita a qualificação como quilombola por motivos mais subjetivos: ou acham que isso seria desonesto para com os que compraram terras no bairro, ou, simplesmente, não querem assumir uma identidade negra e quilombola, lançando mão de um ideário acerca da inexistência de diferenças entre brancos e negros, que é muito facilmente encontrado no senso comum nacional.

Em Bastiões (Iracema - CE), também um bairro rural situado numa serra, acerca de uma hora, de carro, da sede do município, a situação é mais complexa. A comunidade tem poucas famílias que classificaríamos como pretas, uma maioria de famílias que chamaríamos de parda e muitas famílias brancas que vêm comprando terrenos ali, ao longo das décadas. O mito de origem da comunidade se refere a duas negras que ali chegaram, compraram um amplo território e começaram a comunidade. Hoje, as lideranças quilombolas intensamente miscigenadas - reivindicam-se como pertencente às famílias que descendem dessas duas negras e lutam pela titulação coletiva. As famílias brancas que adquiriram, é claro, são contrárias. No entanto, um significativo número de famílias miscigenadas também é contrária, argumentando que não é mais possível separar ali os que são ou não descendentes das fundadoras da comunidade. Por outro lado, a população branca local domina o comércio e não somente oferece empregos em seus estabelecimentos como também atua como atravessadora, levando a produção local para os mercados consumidores. Assim, retirar essas pessoas dali corresponderia, na leitura de muitas famílias miscigenadas, a um esvaziamento econômico que poderia ser prejudicial a muitos deles.

A comunidade de Furnas dos Dionísio (Jaraguari - MS) constitui um conjunto amplo de pequenas propriedade rurais, separadas por cercas e cancelas. As casas são, em geral, distantes umas das outras. O mito de origem se refere ao Dionísio, um escravo que, após conseguir a alforria, comprou muitas terras naquela região. Nessa comunidade, algumas famílias detêm muito mais terra do que outras. Essas famílias - que classificaríamos como compostas por pretos - de fato comercializam propriedades rurais, o que vem, progressivamente, trazendo inúmeros agricultores brancos para dentro da área que, originalmente, foi ocupada pelos descendentes do fundador.

Há uma disputa, permanente, em torno do "ser ou não ser quilombola", não entre pretos e brancos, mas sim entre famílias pretas que possuem grandes áreas de terra e famílias pretas com pouca terra. Esses dois grupos se alternam na liderança da associação comunitária de produtores, que ainda não teve seu nome alterado para incorporar o termo quilombola. As famílias com muita terra argumentam que não querem ser um "quilombo", porque isto traria uma segmentação entre pessoas (brancas e pretas) que são amigas, que convivem lado a lado há muitos anos e que se tratam de igual para igual (é interessante que mesmo as crianças dessas famílias manifestam essa opinião). As famílias com pouca terra 
afirmam que esses argumentos somente escondem o fato de que certas famílias descendentes do fundador acabaram por grilar ou comprar, a preços irreais, terras de outros pretos e lucram com isto.

Há, porém, famílias que, apesar de terem pouca terra, são ligadas por laços de trabalho ou mesmo de compadrio aos que possuem muitas terras. Estas ficam no meio do caminho e resistem em assumir uma posição, foi um membro de uma dessas famílias que, perguntado por mim se era um quilombola, respondeu: - "pode ser."

É curioso que na comunidade de Furnas da Boa Sorte (no município vizinho de Corguinho - MS), a qual teria sido fundada por filhos do Dionísio, muitos moradores critiquem, jocosamente, a liderança das Furnas do Dionísio, por não querer a titulação coletiva como comunidade quilombola, para não ofender a um certo "cumpadre" branco.

\section{CONCLUSÃO}

Não restam maiores dúvidas acerca do fato de que os processos de etnogênese que redundaram na proliferação recente de comunidades quilombolas no Brasil estão ligados, em grande parte, aos direitos e benefícios que as comunidades negras passaram a poder pleitear a partir de 1988 . Nesse processo, a ressemantização do termo "remanescente das comunidades de quilombos" abriu espaço para que, virtualmente, qualquer comunidade rural ou urbana, com maior ou menor presença de negros, lideradas por negros ou brancos (em nossa pesquisa encontramos um número significativo de comunidades quilombolas lideradas por indivíduos que somente poderíamos classificar como brancos) se auto-declarasse como remanescente de quilombos. Esse processo nos leva a discutir, mais uma vez, os limites do que podemos chamar de grupo étnico e, mais ainda, o que podemos compreender como etnicidade.

De início, é importante esclarecer que não estamos fazendo uma defesa das perspectivas que apontam os grupos étnicos como artefatos sociais artificialmente elaborados para fins utilitários. No caso em tela inclusive, proposições desse tipo se mostram ainda mais simplórias, à medida que foram agentes externos às comunidades (primeiro o movimento negro e depois o próprio estado) que alavancaram a etnogênese. A grande questão é compreender como as comunidades conseguem lançar mão de variados elementos que tipicamente se associam à noção de etnicidade para construir matrizes de solidariedade intra-grupo (ainda que de parte do grupo) e reclamar os direitos associados àquela nova condição.

O que tentamos mostrar, neste artigo, é que, à medida que a identidade étnica nada tem de essencial, o importante, para a ciência social, é acompanhar os processos, a partir dos quais as comunidades selecionam e utilizam certos atributos para se mostrar como diferentes. No caso da grande maioria das comunidades por nós investigadas, a etnogênese se encontra em patamares iniciais e as representações e argumentos dos "remanescentes de quilombos" se mostram confusos e desordenados, não perfazendo uma linha discursiva mais sistemática. Podemos apostar que uma volta a essas comunidades, em futuro próximo, deve 
proporcionar um quadro muito diferente do 2007.

que foi encontrado agora.

BRASIL. SECRETARIA DE POLÍTICAS DE PROMOÇÃO DA IGUALDADE RACIAL.

REFERÊNCIAS Programa Brasil Quilombolas. Brasília, 2004. Disponível em:

ARRUTI, J. M. A. A emergência dos <http://www.seppir.gov.br/acoes/pbq>. 'remanescentes': notas para o diálogo entre indígenas e quilombolas. Mana, Rio de Janeio, v. 2, n. 3, p. 7-38, 1997.

BRANDÃO, A. Cotas raciais no Brasil: a primeira avaliação. Rio de Janeiro: DP\&A,

CASTELLS, M. O poder da identidade. São Paulo: Paz e Terra, 1999.

WEBER, M. Economia e sociedade. Brasília: UNB, 2001. 2. v. 